\title{
Formoterol protects against platelet-activating factor-induced effects in asthma
}

\author{
J. Gabrijelcic*, A. Casas*, R.A. Rabinovich*, J. Roca*, J.A. Barberà*, K.F. Chung\#, \\ R. Rodríguez-Roisin*
}

Formoterol protects against platelet-activating factor-induced effects in asthma. J. Gabrijelcic, A. Casas, R.A. Rabinovich, J. Roca, J. Albert Barberà, K.F. Cheng, R. Rodríguez-Roisin. (C)ERS Journals Ltd 2004.

ABSTRACT: Platelet-activating factor (PAF) is an inflammatory mediator that provokes neutropaenia, bronchoconstriction and gas exchange defects due to exudation of bulk plasma within the airways. While the inhibitory effects of short-acting $\beta_{2}$ agonists on PAF-induced disturbances have been consistently shown, those of longacting $\beta_{2}$-agonists are less convincing.

To further explore the mechanisms involved in PAF challenge in asthma, 12 patients (forced expiratory volume in one second, $90 \pm 4 \%$ predicted) were investigated $2 \mathrm{~h}$ after inhaled formoterol $(18 \mu \mathrm{g})$, in a double-blind, placebo-controlled, crossover design following PAF (18 $\mu \mathrm{g})$ inhalation.

Compared with the placebo, at $5 \mathrm{~min}$, premedication with formoterol reduced PAFinduced cough and dyspnoea, and attenuated increased respiratory system resistance (by $67 \%$ ) and arterial deoxygenation (by $50 \%$ ). Likewise, ventilation-perfusion $\left(V^{\prime} \mathrm{A} / Q^{\prime}\right)$ inequality improved, as reflected by the dispersion of pulmonary blood flow (by $63 \%$ ) and an overall index of $V^{\prime} \mathrm{A} / Q^{\prime}$ heterogeneity (by $71 \%$ ). In contrast, PAF-induced facial flushing, neutropaenia and subsequent rebound neutrophilia remained unchanged.

The improvement in gas exchange abnormalities shown after platelet-activating factor in patients with asthma pretreated with formoterol at the recommended clinical dose may reflect, in addition to its class effects, an anti-exudative effect of formoterol in the airways.

Eur Respir J 2004; 23: 71-75.
*Servei de Pneumologia i Al.lèrgia Respiratòria (ICPCT), Institut d'Investigacions Biomèdiques August Pi i Sunyer (IDIBAPS), Hospital Clínic, Universitat de Barcelona, Barcelona, Spain. ${ }^{\#}$ Dept of Thoracic Medicine, National Heart and Lung Institute, Imperial College, London, UK.

Correspondence: R. Rodriguez-Roisin, Servei de Pneumologia i Al.lèrgia Respiratòria, Hospital Clínic, Villarroel, 170, 08036 Barcelona, Spain

Fax: 34932275404

E-mail: roisin@medicina.ub.es

Keywords: Airway obstruction, bronchial challenge, gas exchange, inflammatory mediators, long-acting $\beta_{2}$-agonists

Received: May 262003

Accepted after revision: September 22003

This study was supported by grants $00 / 0617$ from the Fondo de Investigación Sanitaria (FIS), 2001 SGR00286 from the Comissionat per a Universitats i Recerca de la Generalitat de Catalunya, Red de Centros (2003-C03/11) del Ministerio de Sanidad y Consumo (ISCIII), and by grants-in-aid by AstraZeneca, Farmacéutica Spain, and Esteve Group.
Platelet-activating factor (PAF) is a potent ether-linked phospholipid mediator of inflammation, which has been suggested to play a pathogenic role in bronchial asthma [1]. $\mathrm{PAF}$ induces neutropaenia, bronchoconstriction and gas exchange defects due to exudation of bulk plasma within the airways in both normal subjects and asthmatics [2]. These gas exchange abnormalities include the development of areas with low ventilation-perfusion $\left(V^{\prime} \mathrm{A} / Q^{\prime}\right)$ units identical to those shown in patients with spontaneous acute asthma [2-4]. PAF potentiates its effects by generating secondary release of other inflammatory mediators, such as leukotrienes (LT)s, via the activation of phospholipase $\mathrm{A}_{2}[5,6]$.

Both inhaled short-acting and long-acting $\beta_{2}$-agonists (LABA)s remain one of the mainstays of asthma therapy. In addition to their potent bronchodilator effects, these agents also exhibit nonbronchodilator properties, such as anti-exudative efficacy [7, 8]. The current authors have previously shown that inhalation of salbutamol $(300 \mu \mathrm{g})$ is able to suppress all PAF-induced systemic, cellular and functional abnormalities in normal subjects [9] and asthmatics [10]. However, the LABA salmeterol $(50 \mu \mathrm{g}$, b.i.d. $)$ administered for 1 week failed to inhibit neutrophil sequestration and bronchoconstriction caused by PAF [11]. In contrast, the rapid-onset LABA formoterol demonstrated potent antiexudative and bronchodilator properties in healthy individuals [7] and in animal models [12]. Therefore, the authors of this paper investigated the effects of a therapeutic dose of inhaled formoterol fumarate in patients with mild asthma and further explored the systemic, cellular, lung mechanical and gas exchange alterations provoked by PAF inhalation.

\section{Materials and methods}

\section{Subjects}

Twelve nonsmoking, mild asthmatics (eight males; seven atopics) were recruited for the study (table 1) after approval by the Ethical Committee of Hospital Clínic, Barcelona. All patients gave informed written consent after the aims, risks and potential benefits of the study were explained to them. Inclusion criteria were: lack of asthma exacerbation within the preceding 6 weeks; forced expiratory volume in one second (FEV1) $>70 \%$ predicted; positive methacholine bronchial challenge (provocation dose causing a 20\% fall in FEV1 $<1.9 \mu \mathrm{mol})$; positive PAF challenge $(20 \%$ increase of baseline 
Table 1. - Patient anthropometric data

\begin{tabular}{lc}
\hline Age yrs & $24 \pm 1$ \\
Height cm & $170 \pm 2$ \\
Weight kg & $72 \pm 3$ \\
FEV1 L & $3.6 \pm 0.2$ \\
FEV1 \% pred & $90 \pm 4$ \\
PD20 normal $<1.9 \mu \mathrm{mol}$ & $0.7 \pm 0.1$ \\
\hline
\end{tabular}

Data are presented as mean \pm SEM. FEV1: forced expiratory volume in one second; $\%$ pred: $\%$ predicted; PD20: provocative dose of methacholine causing FEV1 to fall $20 \%$ from baseline.

respiratory system resistance (Rrs) 5 min after PAF $(18 \mu \mathrm{g})$ ); maintenance therapy with short-acting $\beta_{2}$-adrenergics (SABA)s and/or inhaled corticosteroids; no previous treatment with systemic steroids; and absence of any systemic or cardiopulmonary disease other than asthma. Maintenance therapy included rescue medication with SABAs alone (four patients) or combined with either regular (four patients) or seasonal inhaled glucocorticoid treatment (three patients); the remaining patient added an oral leukotriene receptor antagonist to seasonal inhaled glucocorticoids and SABAs on clinical demand.

\section{Study drug}

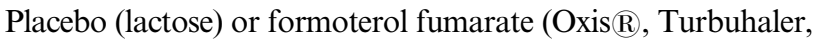
AstraZeneca, Madrid, Spain; $9 \mu \mathrm{g}$ delivered dose, $12 \mu \mathrm{g}$ metered dose) were given as two consecutive inhalations (total dose $18 \mu \mathrm{g}$ ). The patients were given allocation numbers and the order of treatment proceeded according to a randomisation scheme of the allocation numbers prepared in blocks of four. Blindness was maintained by identical appearance of active and vehicle administrations.

\section{Measurements}

$R$ rs was measured by the forced oscillation technique and its analysis restricted to $8 \mathrm{~Hz}[3,4]$. Both minute ventilation and respiratory rate were measured using a calibrated Wright spirometer (Respirometer MK8; BOC-Medical, Essex, UK). A three-lead electrocardiogram, cardiac frequency, and systemic pressure were continuously recorded throughout the whole study (HP 7830A Monitor and HP 7754B Recorder; Hewlett-Packard, Waltham, MA, USA). Both oxygen $\left(\mathrm{O}_{2}\right)$ uptake and carbon dioxide $\left(\mathrm{CO}_{2}\right)$ production were calculated from mixed expired $\mathrm{O}_{2}$ with a Zirconia analyser (MCG Graphics Corporation, St. Paul, $\mathrm{MN}$, USA) and $\mathrm{CO}_{2}$ concentration was measured via a nondispersive infrared analyser (Model CPX/D; MCG Medical Graphics Corporation). Blood samples were collected under anaerobic conditions through a catheter inserted into the radial artery. Arterial $\mathrm{O}_{2}$ tension $\left(\mathrm{Pa}, \mathrm{O}_{2}\right)$, arterial $\mathrm{CO}_{2}$ tension and $\mathrm{pH}$ were analysed in duplicate using standard electrodes, and haemoglobin concentration was measured using a co-oximeter (Ciba corning 860 System; Ciba Corning Diagnostics Corporation, Meadfield, MA, USA). The alveolar-arterial oxygen tension difference $\left(\mathrm{PAa}, \mathrm{O}_{2}\right)$ was calculated according to the alveolar gas equation using the measured respiratory exchange ratio.

The multiple inert gas elimination technique (MIGET) estimated the distributions of $V^{\prime} \mathrm{A} / Q^{\prime}$ ratios without sampling mixed venous inert gases in the customary manner, a modality that can be used with similar accuracy $[13,14]$. Cardiac output was directly measured by dye solution technique (DC410; Waters Instruments Inc., Rochester, MN, USA) using a $5-\mathrm{mL}$ bolus of indocyanine green injected through another catheter placed in a vein of the arm allowing mixed venous inert gas concentrations to be computed from mass balance equations [13]. The duplicate samples of each set of measurements were treated separately, the final data resulting in the average of variables determined from both $V^{\prime} \mathrm{A} / Q^{\prime}$ distributions at each point in time. In one patient, inert gas handling in one of the study days was not reliable.

Total white cell counts in arterial blood were measured with a Technicon H.1 TM System (Technicom, Tarytown, New York, NY, USA), although peripheral blood cells measurements were not available in one patient.

\section{Platelet-activating factor challenge}

A randomised, double-blinded, placebo-controlled, twoperiod crossover design was used. All patients were challenged on two occasions, 1 week apart, with inhaled PAF $2 \mathrm{~h}$ after administration of placebo and formoterol. During the challenge the patients breathed room air and were seated in a semirecumbent position. All asthma medication was withheld $24 \mathrm{~h}$ before the arrival to the laboratory. After the establishment of adequate steady-state conditions, a first set of duplicate measurements was taken (B0). Maintenance of steady-state conditions after PAF challenge was demonstrated by stability $( \pm 5 \%)$ of ventilatory and haemodynamic outcomes, and by the close agreement between duplicate measurements of mixed expired and arterial $\mathrm{O}_{2}$ and $\mathrm{CO}_{2}$ (within $\pm 5 \%$ ). These conditions were present in all patients throughout the entire period of study. Accordingly, the residual sum of squares (RSS) [13], a reliable descriptor of the goodness of the fit of inert gas data, was $4.4 \pm 0.3$ for all MIGET studies following PAF challenge (RSS $<10.6$ in $94 \%$ of sets) [14]. A second set of measurements was made $2 \mathrm{~h}$ after placebo/formoterol administration (B1), and the patient was then challenged with PAF (C16) (1-0-hexadecyl-2-acetylsn-glycero-3-phosphocholine) (18 $\mu \mathrm{g})$ (Novabiochem AG, Laufelfingen, Switzerland). Preparation of the PAF solution and details of the PAF challenge have been previously reported in full [3, 4]. Duplicate measurements were then made at 5, 15, and 45 min after PAF inhalation. All sets of measurements consisted of the following steps in sequence: ventilatory recordings; respiratory and inert gas (mixed venous and arterial) and circulating white blood cells samplings; and haemodynamic and Rrs measurements.

\section{Analysis of data}

Results are expressed as either the arithmetic mean \pm SEM or $95 \%$ confidence interval. Comparison of baseline conditions before and $2 \mathrm{~h}$ after placebo/formoterol and before PAF challenge, and both the effects of PAF challenge and following administration of vehicle/formoterol were assessed using a two-way repeated measures analysis of variance (two-way analysis of variance). Whenever an interaction was found between the effects of PAF challenge and those shown after administration of the two pretreatments, differences between placebo and formoterol at each time point were assessed with a post-hoc paired t-test. A Chi-squared test was used for noncategorical variables (symptoms). Significance was set at $\mathrm{p}<0.05$ in all instances.

\section{Results}

\section{Baseline findings (before platelet-activating factor)}

Anthropometric and functional data were within normal limits and close to those reported in previous studies [15]. 
Table 2. - Baseline data for placebo and formoterol studies

\begin{tabular}{lrr}
\hline & Placebo & Formotero \\
\hline Neutrophils $\times 10^{9} \cdot \mathrm{L}^{-1}$ & $3.3 \pm 0.3$ & $3.3 \pm 0.4$ \\
$R \mathrm{rs} \mathrm{cm} \mathrm{H} \mathrm{O}_{2} \cdot \mathrm{L}^{-1} \cdot \mathrm{s}^{-1}$ & $6.1 \pm 0.5$ & $5.3 \pm 0.4$ \\
$\mathrm{~Pa}, \mathrm{O}_{2} \mathrm{mmHg}$ & $102.4 \pm 3.2$ & $100.3 \pm 2.2$ \\
$P \mathrm{Aa}, \mathrm{O}_{2} \mathrm{mmHg}$ & $2.4 \pm 1.6$ & $2.7 \pm 1.7$ \\
$\operatorname{logSD~Q}$ & $0.48 \pm 0.05$ & $0.46 \pm 0.04$ \\
$\operatorname{logSD~V}$ & $0.45 \pm 0.03$ & $0.44 \pm 0.03$ \\
DISP R-E* & $3.24 \pm 0.48$ & $2.98 \pm 0.41$
\end{tabular}

Data are presented as mean \pm SEM. Rrs: resistance of respiratory system; $\mathrm{Pa}, \mathrm{O}_{2}$ : arterial oxygen tension; $P \mathrm{Aa}, \mathrm{O}_{2}:$ avleolar-arterial oxygen tension difference; $\operatorname{logSD}$ Q: dispersion of pulmonary blood flow distribution; $\operatorname{logSD} \mathrm{V}$ : dispersion of alveolar ventilation distribution; DISP R-E*: retention minus excretion of inert gases corrected for deadspace. $\mathrm{mmHg} \times 0.133=\mathrm{kPa}$.

There were no differences between the placebo and the formoterol subjects (table 2 and fig. 1).

\section{Effects of platelet-activating factor after placebo}

All patients noticed facial flushing and feeling of warmth, nine felt shortness of breath, and six coughed immediately
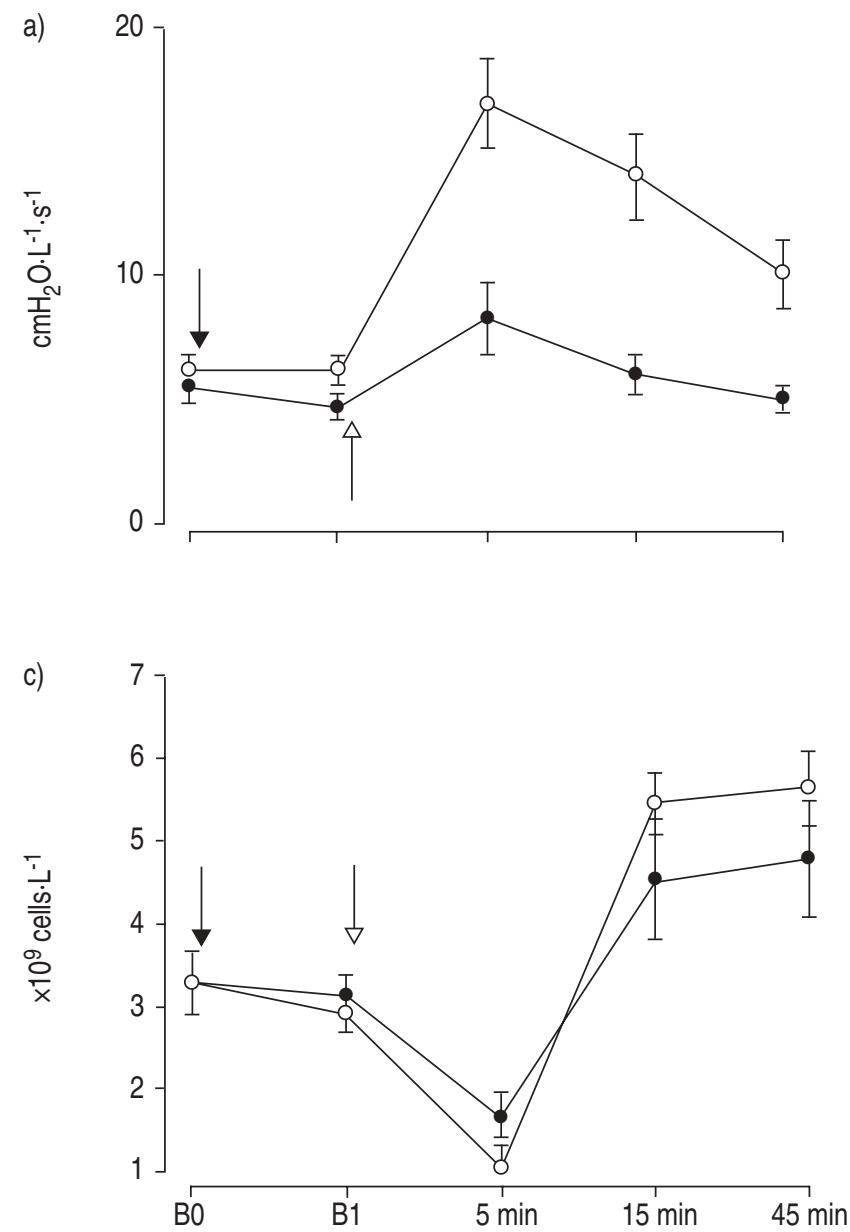

after PAF exposure (table 3 and fig. 1). Compared with formoterol, at $5 \mathrm{~min}, R \mathrm{rs}(\mathrm{p}<0.003)$ and $P A a, \mathrm{O}_{2} \quad(\mathrm{p}<0.05)$ increased and $\mathrm{Pa}_{2} \mathrm{O}_{2}(\mathrm{p}<0.05)$ fell moderately to severely. Arterial deoxygenation was paralleled by the development of moderate-to-severe ventilation/perfusion ratio $\left(V^{\prime} \mathrm{A} / Q^{\prime}\right)$ inequality, as demonstrated by abnormal increases in two of its best descriptors: the dispersion of pulmonary blood flow $(\operatorname{LogSD} \mathrm{Q})(\mathrm{p}<0.02)$ and an overall index of $V^{\prime} \mathrm{A} / Q^{\prime}$ heterogeneity (DISP R-E*) $(\mathrm{p}<0.005)$. At $15 \mathrm{~min}, \operatorname{Rrs}(\mathrm{p}<0.0003)$, $P \mathrm{a}, \mathrm{O}_{2}$ and $P \mathrm{Aa}, \mathrm{O}_{2} \quad(\mathrm{p}<0.01$ each $)$ remained considerably altered and $V^{\prime} \mathrm{A} / Q^{\prime}$ imbalance persisted $(\operatorname{LogSD} \mathrm{Q}, \mathrm{p}<0.02$; DISP R-E*, p<0.001). By $45 \mathrm{~min}, R \mathrm{rs}(\mathrm{p}<0.004), P \mathrm{Aa}, \mathrm{O}_{2}$ $(\mathrm{p}<0.03), \operatorname{LogSD} \mathrm{Q}(\mathrm{p}<0.002)$, and DISP R-E* $(\mathrm{p}<0.01)$ were still mildly increased and $\mathrm{Pa}, \mathrm{O}_{2}$ was slightly reduced $(\mathrm{p}<0.05)$. In contrast, circulating blood neutrophils and ventilatory and haemodynamic parameters, and all the other gas exchange indices, including arterial $\mathrm{pH}$ (at baseline all were within normal limits), remained stable. No patient needed rescue medication.

\section{Effects of platelet-activating factor after formoterol}

Compared to the effect of vehicle, only three patients had dyspnoea $(\mathrm{p}<0.02)$ and one patient had cough $(\mathrm{p}<0.03)$ after $\mathrm{PAF}$; in contrast, facial flushing remained almost unchanged
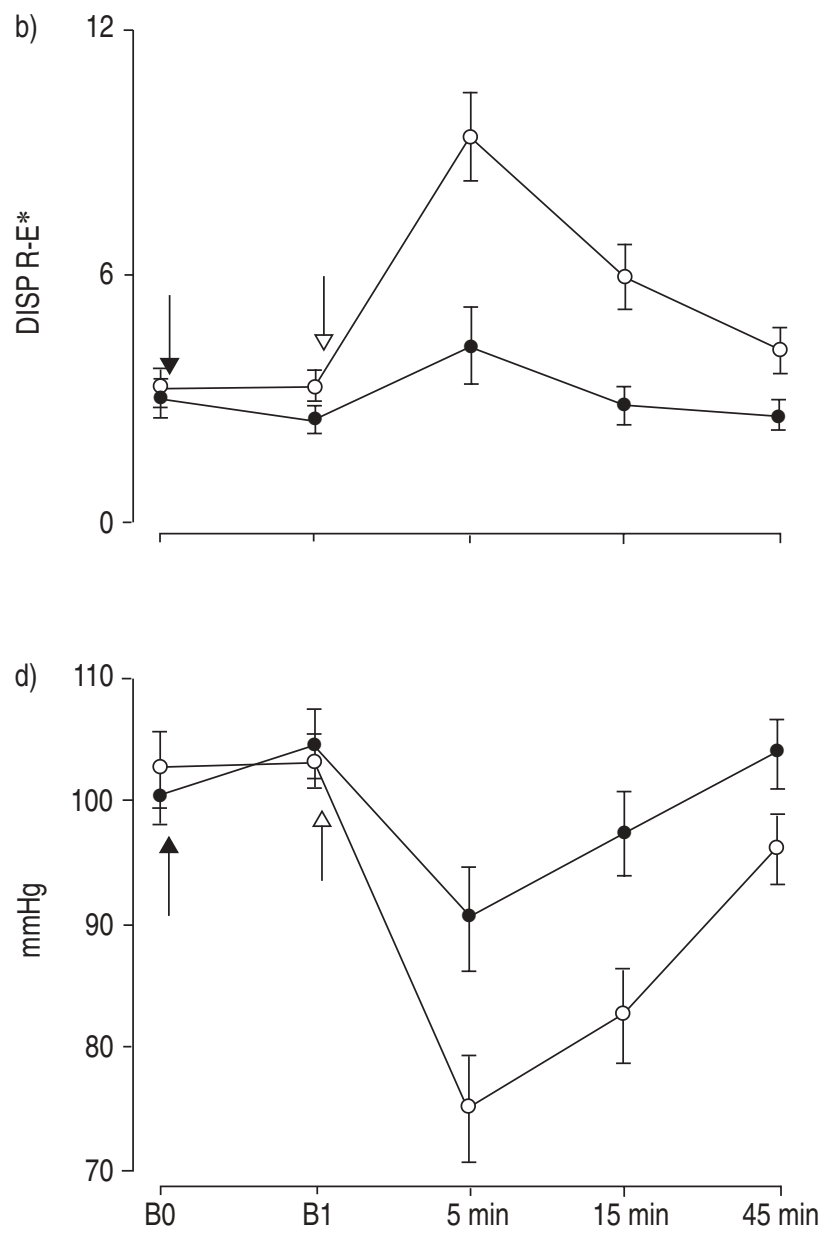

Fig. 1.- Time course of a) respiratory system resistance, b) an overall index of ventilation-perfusion mismatching (expressed as an overall index of ventilation/perfusion ratio heterogeneity (DISP R-E*)), c) peripheral blood neutrophils, and d) arterial oxygen tension before and after platelet-activating factor challenge. Data are presented as mean \pm SEM. $m m H g \times 0.133=\mathrm{kPa}$. BO: baseline measurements before pretreatment; B1: measurements $2 \mathrm{~h}$ after pretreatment, before platelet-activating factor exposure. Closed arrows shows placebo/formoterol administration, open arrows show platelet-activating factor challenge. 0 : formoterol; $\bigcirc$ : placebo. 
Table 3. - Data after placebo $(P)$ and formoterol $(F)$ pretreatments on each platelet-activating factor challenge

\begin{tabular}{|c|c|c|c|c|c|c|}
\hline & & Baseline & $5 \mathrm{~min}$ & $15 \mathrm{~min}$ & $45 \mathrm{~min}$ & p-value $\mathrm{e}^{\#}$ \\
\hline \multirow[t]{2}{*}{ Neutrophils $\times 10^{9} \cdot \mathrm{L}^{-1}$} & $\mathrm{P}$ & $2.9(2.3-3.5)$ & $1.1(0.5-1.6)$ & $5.4(4.6-6.3)$ & $5.6(4.6-6.6)$ & NS \\
\hline & $\mathrm{F}$ & $3.1(2.6-3.7)$ & $1.6(0.9-2.4)$ & $4.6(3.0-6.2)$ & $4.9(3.2-6.6)$ & \\
\hline \multirow{2}{*}{$\operatorname{Rrs~cm~} \mathrm{H}_{2} \mathrm{O} \cdot \mathrm{L}^{-1} \cdot \mathrm{s}^{-1}$} & $\mathrm{P}$ & $6.2(4.9-7.4)$ & $17.0(13.0-21.0)$ & $14.1(10.5-17.7)$ & $10.1(7.04-13.1)$ & 0.0001 \\
\hline & $\mathrm{F}$ & $4.7(3.7-5.7)$ & $8.3 *(5.2-11.4)$ & $6.0 *(4.4-7.6)$ & $5.1 *(4.2-5.9)$ & \\
\hline \multirow[t]{2}{*}{$P \mathrm{a}, \mathrm{O}_{2} \mathrm{mmHg}$} & $\mathrm{P}$ & $103.1(98.2-108.0)$ & $74.9(65.4-84.5)$ & $82.5(74.2-90.9)$ & $96.0(89.8-102.2)$ & 0.02 \\
\hline & $\mathrm{F}$ & $104.5(98.4-110.6)$ & $90.4 *(81.1-99.8)$ & $97.3 *(89.9-104.6)$ & $103.8 *(98.1-109.6)$ & \\
\hline \multirow[t]{2}{*}{$\mathrm{PAa}, \mathrm{O}_{2} \mathrm{mmHg}$} & $\mathrm{P}$ & $1.8(-0.1-4.3)$ & $27.7(18.2-37.3)$ & $18.5(8.9-28.2)$ & $5.8(0.1-11.6)$ & 0.009 \\
\hline & $\mathrm{F}$ & $1.5(-0.7-3.6)$ & $11.9 *(1.3-22.4)$ & $5.9 *(0.1-11.7)$ & $1.7(-0.1-4.1)$ & \\
\hline \multirow[t]{2}{*}{$\operatorname{LogSD} Q$} & $\mathrm{P}$ & $0.49(0.40-0.57)$ & $1.01(0.80-1.21)$ & $0.80(0.64-1.00)$ & $0.63(0.51-0.76)$ & 0.02 \\
\hline & $\mathrm{F}$ & $0.41(0.33-0.48)$ & $0.59 *(0.37-0.82)$ & $0.52 *(0.33-0.69)$ & $0.43 *(0.35-0.52)$ & \\
\hline \multirow[t]{2}{*}{ DISP R-E $E^{\#}$} & $\mathrm{P}$ & $3.31(2.50-4.12)$ & $9.38(7.01-11.74)$ & $5.95(4.17-7.74)$ & $4.14(2.96-5.32)$ & 0.001 \\
\hline & $\mathrm{F}$ & $2.50(1.75-3.26)$ & $4.28 *(2.23-6.32)$ & $2.87 *(1.83-3.80)$ & $2.61 *(1.93-3.28)$ & \\
\hline
\end{tabular}

Data are presented as mean $(95 \%$ confidence interval) unless otherwise stated. All data correspond to 12 patients, except for neutrophil and inert gas variables $(\mathrm{n}=11)$. $\mathrm{mmHg} \times 0.133=\mathrm{kPa}$. Rrs: resistance of respiratory system; $P \mathrm{a}, \mathrm{O}_{2}$ : arterial oxygen tension; $P A a, \mathrm{O}_{2}$ : alveolar-arterial oxygen tension difference; logSD Q: dispersion of pulmonary blood flow distribution; DISP R-E: retention minus excretion inert gases corrected for deadspace; NS: not significant. \#: Significance of the interaction between the effects of platelet-activating factor challenge and pretreatment with placebo and formoterol using a two-way repeated measures analysis of variance. *: $\mathrm{p}<0.05$ for comparison with placebo.

with no response in two patients (table 3 and fig. 1). At $5 \mathrm{~min}$, PAF-induced increases in $R$ rs (by 67\%) and $\mathrm{PAa}_{2} \mathrm{O}_{2}$ (by $53 \%$ ) and hypoxaemia (by 50\%) were substantially attenuated; similarly both abnormal LogSD Q (by 63\%) and DISP R-E* (by $71 \%$ ) were largely ameliorated. By $15 \mathrm{~min}, R$ rs (by $85 \%$ ), $\mathrm{Pa}_{2} \mathrm{O}_{2}$ (by $58 \%$ ), $P \mathrm{Aa}, \mathrm{O}_{2}$ (by $71 \%$ ), and $V^{\prime} \mathrm{A} / Q^{\prime}$ inequality continued to improve and all gas exchange markers were already within normal limits. At $45 \mathrm{~min}$, all these outcomes were normalised. Abnormal neutrophil kinetics remained unaltered throughout the study.

\section{Discussion}

The novel finding of the current study was that, in addition to inhibiting bronchoconstriction, a clinically recommended dose of inhaled formoterol used in patients with mild asthma considerably protected against arterial deoxygenation and underlying ventilation-perfusion imbalance after PAF. In contrast, formoterol was unable to modulate either facial flushing or neutrophil kinetics. Based on previous work by the authors in both normal subjects $[3,8,9]$ and mild asthmatics $[4,10,15]$, the authors postulate that PAF-induced pulmonary gas exchange defects and increases of $R \mathrm{rs}$ are related to airway narrowing secondary to abnormally increased microvascular leakage, rather than to a primary constrictor effect on airway smooth muscle. SABAs were among the first agents to exhibit anti-oedema effects by preventing separation of endothelial cells at postcapillary venular sites [16]. Inhaled salbutamol at a dose of $300 \mu \mathrm{g}$ [10], but not at a lower dose [17], or the anticholinergic ipratropium bromide $(80 \mu \mathrm{g})$, was efficacious in completely antagonising PAF-induced effects in patients with asthma.

Anti-exudative effects have been also shown with the use of LABAs [8, 18-20], suggesting airway anti-inflammatory activity. Likewise, LABAs reduce the adhesion of inflammatory eosinophils and neutrophils to endothelial cells [21] and restrain their traffic from the vascular to the airway compartment $[18,22] . \beta_{2}$ agonists are efficacious when given by inhalation in animal models, suggesting inhibition of airway plasma exudation [22]. In normal subjects, salmeterol (50 $\mu \mathrm{g}$ b.i.d. for 1 week) was ineffective in blocking neutrophil kinetics and bronchoconstriction induced by PAF [11], possibly because of the induction of tachyphylaxis related to repeated dosing. However, a single dose of formoterol $(24 \mu \mathrm{g})$ in normal subjects prevented PAF-induced FEV1 and neutropaenia [23], suggesting that formoterol may have, in addition to its class effects, nonbronchodilator properties. In an in vitro study of neutrophils exposed to PAF, formoterol possessed weaker membrane-stabilising properties but higher intrinsic activity than salmeterol, characteristic of a full $\beta_{2}$ receptor agonist [24]. Formoterol, unlike salmeterol, induces a dose-related response and exhibits a faster onset of action than salmeterol, which may be attributable to its physicochemical properties [8, 25]. Moreover, formoterol reversed methacholine-induced bronchoconstriction as rapidly as salbutamol, and more rapidly than salmeterol [25]. Formoterol showed slightly greater potency over salbutamol against PAF-induced extravasation and bronchoconstriction in guinea pigs [26]. However, compared with formoterol, both salmeterol and salbutamol exhibited the greatest inhibition on neutrophil accumulation at a lower dose [27]. $\beta_{2}$ receptors are present on neutrophils and LABAs have been shown to affect different facets of neutrophil activation [8]. Moreover, LABAs may induce neutrophil apoptosis, an effect mediated via activation of $\beta_{2}$ receptors [8]. This is supported by a recent study in mild asthmatics, in which salmeterol $(50 \mu \mathrm{g}$ b.i.d. for 6 weeks) significantly reduced the number of neutrophils in bronchial biopsies [28]. Lastly, formoterol has been also shown to be as effective, safe and well tolerated as terbutaline, in patients with acute bronchoconstriction caused by asthma and chronic obstructive pulmonary disease [29].

Notwithstanding, formoterol was ineffective in antagonising PAF-induced neutrophil kinetics and facial flushing. This suggests that other mediators, such as LTs, may be involved. Moreover, LTs may be involved secondarily in the production of some of the systemic and pulmonary effects caused by PAF in asthmatic patients $[5,6]$. PAF can increase the subsequent release of chemotactic mediator $\mathrm{LTB}_{4}$ [5], which is significantly increased in the sputum of patients with asthma challenged with PAF [21]. Alternatively, the absence of efficacy on peripheral blood neutrophils and facial flushing in the current study may just reflect dose-dependency. It may well be that the use of a higher dosage of formoterol (i.e. $36 \mu \mathrm{g})$ might exhibit superior inhibitory effects, a view that cannot be neglected.

In summary, by protecting against arterial deoxygenation, formoterol fumarate reinforces its role in the current strategic therapy of asthma with long-acting $\beta_{2}$ agonists. Conceivably, gas exchange improvement after platelet-activating factor may reflect a decrease of microvascular plasma exudation in the peripheral airways of patients with asthma. The demonstration of anti-exudative efficacy by inhaled formoterol, at the recommended clinical doses, may add further evidence to 
previous suggestions [7] that a vascular antipermeability property can be an important step of its mechanisms of therapeutic effect of long-acting $\beta_{2}$ agonists in asthma. Antiexudative properties of long-acting $\beta_{2}$ agonists may enhance their antiasthma efficacy beyond bronchodilation and add potential for reducing asthma exacerbations [30].

\footnotetext{
Acknowledgements. The authors are also grateful to C. Barcina (AstraZeneca, Farmacéutica, Madrid, Spain) for his facilities in the development of the study.
}

\section{References}

1. Chung KF. Platelet activating factor in inflammation and pulmonary disorders. Clin Sci 1992; 83: 127-138.

2. Rodriguez-Roisin R. Acute severe asthma: pathophysiology and pathobiology of gas exchange abnormalities. Eur Respir $J$ 1997; 10: 1359-1371.

3. Rodriguez-Roisin R, Félez MA, Chung KF, et al. Plateletactivating factor causes ventilation-perfusion mismatch in humans. J Clin Invest 1994; 93: 188-194.

4. Félez MA, Roca J, Barberà JA, et al. Inhaled platelet activating factor worsens gas exchange in mild asthma. Am J Respir Crit Care Med 1994; 150: 369-373.

5. Shindo K, Koide K, Fukumura M. Platelet-activating factor increases leukotriene $B_{4}$ release in stimulated alveolar macrophages from asthmatic patients. Eur Respir J 1998; 11: 1098-1104.

6. Echazarreta AL, Gómez F, Ribas J, et al. Effects of inhaled furosemide on platelet-activating factor challenge in mild asthma. Eur Respir J 1999; 14: 616-621.

7. Greiff L, Wollmer $\mathrm{P}$, Andersson $\mathrm{M}$, et al. Effects of formoterol on histamine induced plasma exudation in induced sputum from normal subjects. Thorax 1998; 53: 1010-1013.

8. Johnson M, Rennard S. Alternative mechanisms for longacting beta 2 -adrenergic agonists in COPD. Chest 2001; 120 : 258-270.

9. Roca J, Félez MA, Chung KF, et al. Salbutamol inhibits pulmonary effects of platelet activating factor in man. Am J Respir Crit Care Med 1995; 151: 1740-1744.

10. Díaz O, Barberà JA, Marrades R, et al. Inhibition of PAFinduced gas exchange defects by beta-adrenergic agonists in mild asthma is not due to bronchodilatation. Am J Respir Crit Care Med 1997; 156: 17-22.

11. Spring J, Johnston SR, Seale J, et al. Failure of salmeterol to inhibit circulating white cell responses and bronchoconstriction induced by platelet activating factor. Thorax 1992; 47: 948-951.

12. Sulakvelidze I, McDonald DM. Anti-edema action of formoterol in rat trachea does not depend on capsaicin sensitive sensory nerves. Am J Respir Crit Care Med 1994; 149: 232-238.

13. Roca J, Wagner PD. Contributions of multiple inert gas elimination technique to pulmonary medicine: 1 . Principles and information content of the multiple inert gas. Thorax 1994; 49: 815-824.

14. Glenny R, Wagner PD, Roca J, Rodríguez-Roisin R. Gas exchange in health: rest, exercise, and aging. In: Roca J, Rodríguez-Roisin R, Wagner PD, eds. Pulmonary and peripheral gas exchange in health and disease. New York, Marcel Dekker Inc., 2000: pp. 121-148.

15. Acuña AA, Gabrijelcic J, Uribe EM, et al. Fluticasone propionate attenuates PAF-induced gas exchange defects in mild asthma. Eur Respir J 2002; 19: 872-878.

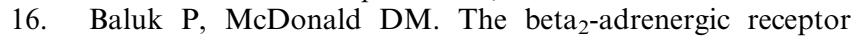
agonist formoterol reduces microvascular leakage by inhibiting endothelial gap formation. Am J Physiol 1994; 266: 461468.

17. Chung KF, Barnes PJ. Effects of platelet-activating factor on airway calibre, airway responsiveness, and circulating cells in asthmatic subjects. Thorax 1989; 44: 108-115.

18. Erjefalt I, Persson CG. Long duration and high potency of antiexudative effects of formoterol in guinea-pig tracheobronchial airways. Am Rev Respir Dis 1991; 144: 788791

19. Bolton PB, Lefevre P, McDonald DM. Salmeterol reduces early- and late-phase plasma leakage and leukocyte adhesion in rat airways. Am J Respir Crit Care Med 1997; 155: 14281435.

20. Bowden JJ, Sulakvelidze I, McDonald DM. Inhibition of neutrophil and eosinophil adhesion to venules of rat trachea by $\beta_{2}$-adrenergic agonist formoterol. J Appl Physiol 1994; 77: $397-405$.

21. Gabrijelcic J, Acuña A, Profita M, et al. Neutrophil airway influx by platelet-activating factor in asthma: role of adhesion molecules and $\mathrm{LTB}_{4}$ expression. Eur Respir $J$ 2003; 22: 290-297.

22. Boschetto P, Roberts NM, Rogers DF, et al. The effect of anti-asthma drugs on microvascular leak in guinea pig airways. Am Rev Respir Dis 1988; 139: 416-421.

23. Wort SJ, Shakur BH, Ind P. Formoterol protects against the neutropenia induced by platelet activating factor in humans (abstract). Eur Respir J 1998; 12: Suppl. 28, 323s.

24. Anderson R, Feldman C, Theron AJ, et al. Anti-inflammatory membrane-stabilizing interactions of salmeterol with human neutrophils in vitro. Br J Pharmacol 1996; 117: 1387-1394.

25. Politiek MJ, Boorsma A, Aalbers R. Comparison of formoterol, salbutamol and salmeterol in methacholineinduced severe bronchoconstriction. Eur Respir J 1999; 13: 988-992.

26. Sakamoto T, Barnes PJ, Chung KF. Effect of beta $2_{2}$ adrenoceptor agonist on platelet-activating factor-induced airway microvascular leakage and bronchoconstriction in the guinea pig. Agents Actions 1993; 40: 50-56.

27. Whelan CJ, Johnson M, Vardley CJ. Comparison of the anti-inflammatory properties of formoterol, salbutamol and salmeterol in guinea-pig skin and lung. Br J Pharmacol 1993; 110: 613-618.

28. Jeffery PK, Venge P, Gizycki MJ, et al. Effects of salmeterol on mucosal inflammation in asthma: a placebo-controlled study. Eur Respir J 2002; 20: 1378-1385.

29. Malolepszy J, Böszörményi Nagy G, Selroos O, et al. Safety

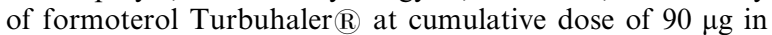
patients with acute bronchial obstruction. Eur Respir J 2001; 18: 928-934

30. Pauwels RA, Löfdahl C-G, Postma DS, et al. Effect of inhaled formoterol and budesonide on exacerbations of asthma. N Engl J Med 1997; 337: 1405-1411. 